\title{
Application of OCT to Examination of Easel Paintings
}

\author{
Haida Liang ${ }^{* a}$, Rada Cucu ${ }^{\mathrm{b}}$, George M. Dobre ${ }^{\mathrm{b}}$, David A. Jackson ${ }^{\mathrm{b}}$, Justin Pedro ${ }^{\mathrm{c}}$, \\ Chris Pannell ${ }^{\text {, }}$, David Saunders ${ }^{\mathrm{a}}$, Adrian Gh. Podoleanu ${ }^{\mathrm{b}}$ \\ ${ }^{a}$ Scientific Dept., The National Gallery, Trafalgar Square, London WC2N 5DN, UK; \\ ${ }^{\mathrm{b}}$ Applied Optics Group, School of Physical Sciences, University of Kent, Canterbury, CT2 7NR, UK \\ ${ }^{\mathrm{c}}$ Ophthalmic Technologies Inc., Toronto, Canada \\ ${ }^{\mathrm{d}}$ Gooch \& Housego Group, Optronic Laboratories Inc., $463236^{\text {th }}$ Street, Orlando, Florida 32811 , \\ USA
}

\begin{abstract}
We present results of applying low coherence interferometry to gallery paintings. Infrared low coherence interferometry is capable of non-destructive examination of paintings in 3D, which shows not only the structure of the varnish layer but also the paint layers.
\end{abstract}

Keywords: Low coherence interferometry, optical coherence tomography, antiquities, art conservation

\section{INTRODUCTION}

Scientific examinations of easel paintings are routinely carried out in major galleries and museums to assist in conservation treatment and as part of technical or art historical examinations. Care is taken to examine the paintings nondestructively as far as possible, though it is sometimes still necessary to take tiny samples from paintings for analysis. Examples of non-destructive examination include X-radiography and infrared reflectography. X-radiography is routinely employed to examine the structure of the support of a painting, as well as details of areas painted with pigments containing heavy elements. Infrared reflectography is one of the most useful techniques for art historians studying the preparatory drawings or underdrawings underneath the painted layers, which would be otherwise invisible to the eye. Infrared reflectography normally operates in the wavelength range of 0.8 to $2 \mu \mathrm{m}$, where most of the paint layers are relatively transparent, but the carbon-based materials often used in drawings absorb strongly. Both techniques collapse the $3 \mathrm{D}$ information of a painting into $2 \mathrm{D}$, thus losing the detailed information perpendicular to the painting plane. Hence, in order to study the paint and varnish layers, it is still currently necessary to take tiny samples of a painting to examine the cross section of a small area of the painting under a microscope.

Recently, efforts have been made to find alternative methods for pigment identification using mutli-spectral imaging techniques (e.g. Berns and Imai ${ }^{1}$, Liang et al. $^{2}$ ), which are non-destructive and non-contact. However, in order to retrieve the true spectral reflectance of the pigments, it is necessary to 'subtract' the optical effects of the varnish layer that is normally applied above the paint layers. Varnish layers are usually applied to paintings for both protective and aesthetic purposes. Application of a varnish layer to an oil painting not only gives it a uniform gloss, but also increases its colour saturation, contrast and clarity. However, as the varnish layers on oil paintings age they become yellow and form cracks, which result in darkening or increased haziness. Consequently, it is necessary to clean the aged varnish off to reveal the true colours of paintings. However, the removal of a varnish layer can be very time consuming, and there is also a slight danger of the solvents used in cleaning the varnish layer affecting the paint layers. In a recent study of the relative importance of surface roughness and refractive index in the appearance of varnished paintings, Berns and de la Rie ${ }^{3}$ found that the dominant optical parameter was a varnish's ability to level a roughened paint surface. In general, the lower the molecular weight, the better the varnish is able to level a rough surface. Varnishes with a high refractive index and low molecular weight are thought to be more desirable, hence the preference for natural resins such as dammar and mastic.

\footnotetext{
* haida.liang@ng-london.org.uk; phone 44207747 2570; fax 44207839 3897; www.nationalgallery.org.uk
} 
Given that the optical thickness of the varnish and its success in reducing underlying surface roughness will affect the optical properties of the painting, including its colour saturation, and that the optical depth will also affect the degree of yellowing imparted by a discoloured varnish, it would be extremely useful for museums and galleries to have at their disposal an efficient means of measuring the varnish optical thickness and surface roughness non-destructively.

In an attempt to solve the problem we have used an low coherence interferometry to resolve the spatial distribution of layers in depth. This is similar to the principle of Optical Coherence Tomography (OCT) ${ }^{4}$ widely applied in the noninvasive imaging of tissue. We have used two OCT systems capable of producing depth resolved 3D images. These systems are similar to those used to image medical structures such as the retina reported in Podoleanu $e a^{5}$, using single mode fibre couplers ${ }^{6}$.

Laser interferometry such as holography and speckle interferometry have been applied to works of art to detect structural defects. However, since these methods employ a laser source which has high temporal coherence, they do not offer the ability to distinguish between successive reflective layers. A wide band source with high spatial coherence used in OCT can overcome most of these difficulties offering the opportunity to study the cross-section of the paint and varnish layers. Recently Targowski et $\mathrm{l}^{7}$ reported the use of OCT for a similar application.

\section{TEST TARGETS}

\subsection{TEST SAMPLES}

A series of sample boards to which oil paint layers had been applied was prepared. Films of dammar or mastic varnish were applied to either side of the sample leaving the centre region unvarnished (see Fig. 1). In some of the samples the paint patches were applied with a brush, simulating a real painting, where the depth varies from point to point, while in others a film-spreader was used to give an ideal situation where the depth is uniform. Different pigments covering a broad colour range were used to test whether the measurements would be independent of the absorption characteristics of the underlying paint layers. The pigment mixtures and layer combinations reflect those found in real oil paintings. Ground, paint and varnish layers were painted onto six 7 × $8.5 \mathrm{~cm}$ Teflon (PTFE) boards. The surface of each Teflon board was sanded so that the ground layer would be able to bind to it. A traditional painting ground was made by the addition of chalk to warmed rabbit skin glue. Teflon boards were either covered by spreading the ground to a thickness of $200 \mu \mathrm{m}$, or by brushing it on. Once dry, the ground was sealed by the application of two size layers so that the oil from the oil paint was not absorbed into the porous chalk ground. Diluted rabbit skin glue was used as the size. Two pigments were then painted onto each board.

\subsection{TEST PAINTING}

A roughly 50-year-old test painting, which has half the aged yellow varnish removed, was used to test the technique on a real painting (see Fig. 2). Two small patches of new mastic and dammar varnish were applied to the top left hand corner of the painting where the old varnish had been removed.
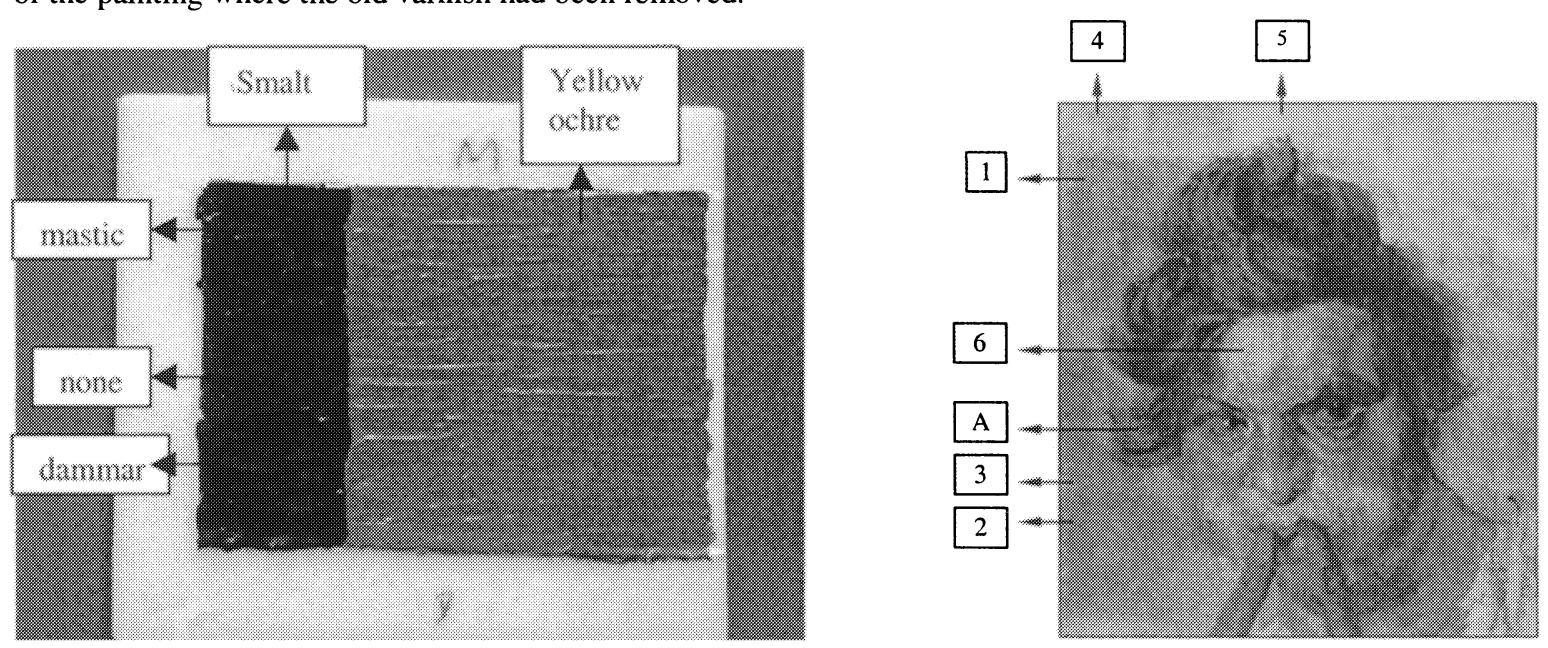
Figure 1: Sample board of yellow ochre and smalt (dark blue in colour) on a ground layer of chalk and rabbit skin glue. One third of the sample has three coats of dammar varnish applied, and another one third of the painting has 3 coats of mastic varnish applied, leaving the central part of the sample unvarnished (marked 'none').
Figure 2: A 50-year-old test painting: Points 1, 2, 3,6 , and A were covered with the original varnish, which is now yellowed; point 6 has a rough paint surface; point 4 is covered in new mastic varnish; point 5 is unvarnished.

\section{RESULTS}

Selected points on the sample board shown in Fig.1 and on the test painting (Fig. 2) were imaged using OCT.

The thickness of a varnish sample applied to glass in 1952 was measured independently by making a cross-section and viewing this under a microscope. This measurement found a varnish thickness of $80-100 \mu \mathrm{m}$, which is consistent with the thickness measured by OCT (see Fig. 6). Varnish thickness measurements at point A on the test painting (Fig. 2) using OCT systems working at $800 \mathrm{~nm}$ and $1300 \mathrm{~nm}$ were consistent with each other and found to be $\sim 80 \mu \mathrm{m}$ in the thicker regions, which is also consistent with the measurements made by cross-sectional analysis.

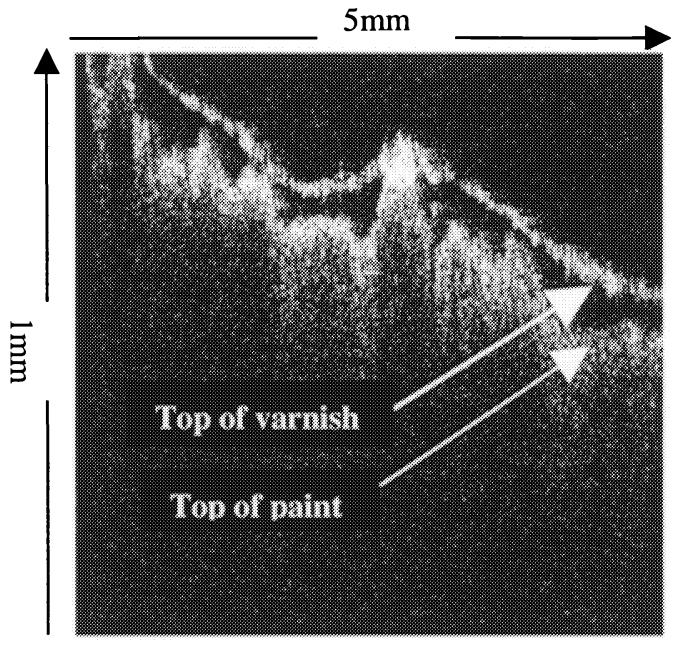

Figure 3 An $800 \mathrm{~nm}$ OCT image at point $\mathrm{A}$ on the test painting showing a well delineated varnish layer on top of the paint layer and also showing the microscopic variation in the structure of both the paint and varnish layers. The vertical scale represents depth measured in air.

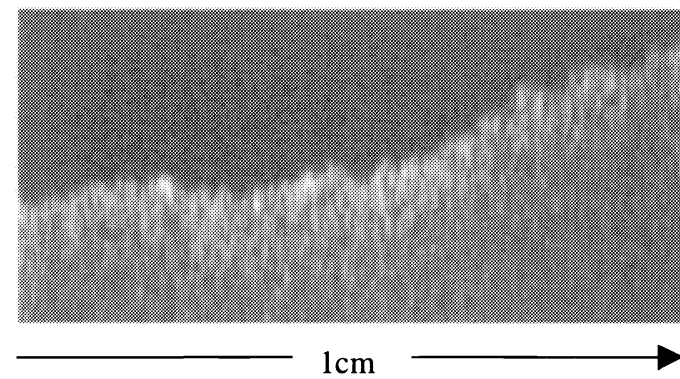

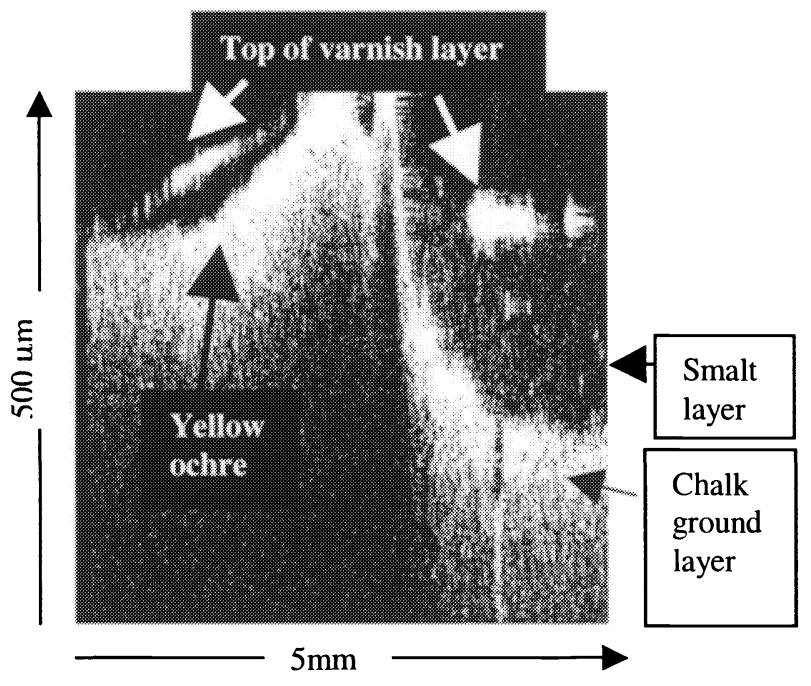

Figure 4: An $800 \mathrm{~nm}$ OCT image of the sample board shown in Fig. 2, at the edge between the smalt and yellow ochre paint areas. Smalt is transparent to $800 \mathrm{~nm}$ radiation, which allows the ground layer of chalk to be detected underneath the smalt layer. Yellow ochre is less transparent at $800 \mathrm{~nm}$, and the ground layer cannot be detected beneath the yellow ochre paint layer. The vertical scale represents depth measured in air.

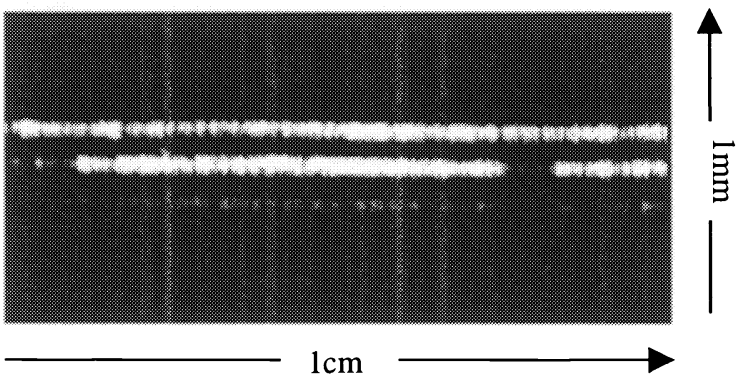


Figure 5: A 1300nm OCT image at point 5 on the test painting, showing a bare paint layer (which was expected, since the varnish had been cleaned off that area). The vertical scale represents depth measured in air.
Figure 6: A 1300nm OCT image of a mastic varnish layer on a piece of glass dating from 1952; the varnish/air and varnish/glass interfaces are clearly delineated. The vertical scale represents depth measured in air.

The $1300 \mathrm{~nm}$ OCT measurement of point 5 on the test painting confirmed that there was no varnish in that area. Fig. 4 shows the potential of an infrared OCT in obtaining cross-section information on paintings. The $800 \mathrm{~nm}$ OCT instrument was used to scan across the boundary between the yellow ochre and smalt paints on the sample board (Fig. 1); the smalt area is to the right and the yellow ochre area is to the left. The transparency of smalt to radiation at $800 \mathrm{~nm}$ enables the OCT to see through it and measure the tomography of the ground layer beneath.

\section{CONCLUSIONS}

The OCT images present better microscopic tomography of the surface of the varnish and paint layers than any other system currently employed in the examination of easel paintings. OCT also provides an accurate measure of the thickness of the varnish layer on a painting; its advantage over normal cross-section examination under a microscope being that it would be possible to make a thickness measurement across the surface of the paintings rather than only at those discrete points selected for sampling. Infrared OCT has the potential to provide a 3D infrared reflectogram during the examination of a painting which would not only show the underdrawings underneath the paint layers, but also provide information on the structure of the paint and varnish layers. It might therefore be possible to see, without taking samples, the extent to which a particular layer overlapped another and to make sense of the layer sequence in cases where the painting displayed a complex stratigraphy.

\section{ACKNOWLEDGEMENTS}

H.L. would like to thank Marika Spring for help with cross-section measurements, and Emily Gore for preparing the painted samples.

\section{REFERENCES}

1. R.S. Berns, and F.H. Imai, 'The use of multi-channel visible spectrum imaging for pigment identification', in ICOM Committee for Conservation, 13th Triennial Meeting, Rio de Janeiro (2002) 217-222.

2. H. Liang, D. Saunders, J. Cupitt, M. Benchouika, 'A new multi-spectral imaging system for examining paintings', to appear in IS\&T's Second Conference on Color in Graphics, Imaging and Vision (CGIV 2004), Aachen, 2004.

3. R. S. Berns, and E.R. de la Rie, 'Exploring the optical properties of picture varnishes using imaging techniques', Studies in Conservation, Vol. 48, No. 2, 2003, 73-83.

4. D. Huang, E. A. Swanson, C. P. Lin, J. S. Schuman, W. G. Stinson, W. Chang, M. R. Hee, T. Flotte, K. Gregory, C. A. Puliafito, J. G. Fujimoto, 'Optical coherence tomography', Science, Vol. 254, 1991, 1178-1181.

5. A. Gh. Podoleanu, J. A. Rogers, D. A. Jackson and S. Dunne, 'Three dimensional OCT images from retina and skin' Opt. Express, Vol. 7, No. 9, p. 292-298, (2000), http://www.opticsexpress.org/framestocv7n9.htm

6. A. Gh. Podoleanu, M. Seeger, G. M. Dobre, D. J. Webb, D. A. Jackson, F. Fitzke, `Transversal and longitudinal images from the retina of the living eye using low coherence reflectometry', J. Biomed Optics, Vol. 3, 1998, 12-20.

7. P. Targowski, B. Rouba, M. Wojtkowski, and A. Kowalczyk, 'The application of Optical Coherence Tomography to non-destructive examination of museum objects', Studies in Conservation, Vol. 49, No. 1, 2004, in press. 